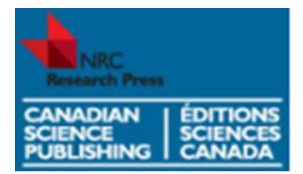

Applied Physiology,

Nutrition, and Metabolism

Physiologie appliquée,

nutrition et métabolisme

\title{
Increased blood cholesterol after a high saturated fat diet is prevented by aerobic exercise training
}

\begin{tabular}{|r|l|}
\hline Journal: / Journal : & Applied Physiology, Nutrition, and Metabolism \\
\hline $\begin{array}{r}\text { Manuscript ID: / ID du } \\
\text { manuscrit : }\end{array}$ & $2012-0123 . R 2$ \\
\hline $\begin{array}{r}\text { Manuscript Type: } \\
\text { Date Submitted by the Author: } \\
\text { / Date de soumission de } \\
\text { I'auteur : }\end{array}$ & n/a \\
\hline $\begin{array}{r}\text { Complete List of Authors: / } \\
\text { Compléter la liste des auteurs } \\
:\end{array}$ & $\begin{array}{l}\text { Ortega, Juan Fernando; University of Castilla-La Mancha, } \\
\text { Hamouti, Nassim; University of Castilla-La Mancha } \\
\text { Mora-Rodriguez, Ricardo; University of Castilla La Mancha, }\end{array}$ \\
\hline Keyword: & $\begin{array}{l}\text { exercise training < exercise, LDL, Atherogenic diet, insulin resistance, } \\
\text { OGTT }\end{array}$ \\
\hline \multicolumn{2}{|c}{}
\end{tabular}




\section{ABSTRACT}

2 A high saturated fatty acids diet (HSFAD) deteriorates metabolic and cardiovascular health

3 while aerobic training improves them. The aim of this study was to investigate in physically

4 inactive, overweight people if two weeks of HSFAD leads to hyperlipemia or insulin resistance

5 and if concurrent aerobic exercise training counteracts those effects. Fourteen overweight

6 (BMI: $\left.27.5 \pm 0.6 \mathrm{~kg} \cdot \mathrm{m}^{-2}\right)$ healthy-young individuals $(24.8 \pm 1.8 \mathrm{yr}$ old) were randomly assigned to

7 a diet (D) or a diet plus exercise (D+E) group. During 14 consecutive days both groups

8 increased dietary saturated fatty acids from $31 \pm 10$ to $52 \pm 14{\mathrm{~g} \cdot \text { day }^{-1}}^{(\mathrm{P}<0.001) \text { while }}$

9 maintaining total fat intake. Concurrent to the diet, the D+E group underwent 11 cycle-

10 ergometer sessions of $55 \mathrm{~min}$ at $60 \% \mathrm{~V} \mathrm{O}_{2 \text { peak }}$. Before and after intervention insulin sensitivity

11 was estimated and body composition, plasma lipid profile, free fatty acids (FFA) composition,

12 resting blood pressure (BP) and $\mathrm{V} \mathrm{O}_{\text {2peak }}$ were measured. Body weight and composition,

13 plasma FFA composition and insulin sensitivity remained unchanged in both groups.

14 However, total cholesterol $\left(\mathrm{T}_{\mathrm{C}}\right)$ and low-density lipoprotein cholesterol (LDL-C) increased

15 above pre-intervention values in the $\mathrm{D}$ group $\left(147 \pm 8\right.$ to $161 \pm 9 \mathrm{mg} \cdot \mathrm{dL}^{-1}, \mathrm{P}=0.018$ and $71 \pm 10$ to

$1682 \pm 10 \mathrm{mg} \cdot \mathrm{dL}^{-1}, \mathrm{P}=0.034$, respectively). In contrast, in the $\mathrm{D}+\mathrm{E}$ group, $\mathrm{T}_{\mathrm{C}}$ and $\mathrm{LDL}-\mathrm{C}$ remained

17 unchanged $\left(153 \pm 20\right.$ to $157 \pm 24 \mathrm{mg} \cdot \mathrm{dL}^{-1}$ and $71 \pm 21$ to $\left.70 \pm 25 \mathrm{mg} \cdot \mathrm{dL}^{-1}\right)$. Additionally the $\mathrm{D}+\mathrm{E}$

18 group lowered systolic $\mathrm{BP}(6 \pm 2 \mathrm{mmHg}, \mathrm{P}=0.029)$ and increased $\mathrm{V} \mathrm{O}_{2 \text { peak }}\left(6 \pm 2 \mathrm{ml} \cdot \mathrm{kg}^{-1} \cdot \mathrm{min}^{-1}\right.$,

$19 \mathrm{P}=0.020)$. Increases in $\mathrm{T}_{\mathrm{C}}$ and LDL-C induced by 14 days of HSFAD can be prevented by

20 concurrent aerobic exercise training that in addition improves cardio-respiratory fitness.

21

22 Key words: Exercise training, LDL, Atherogenic diet, Insulin sensitivity, OGTT. 


\section{INTRODUCTION}

2 A high-fat diet is associated with the development of obesity and an atherogenic blood

3 lipid profile which increase the risk of developing cardiovascular and metabolic diseases

4 (Nishida et al. 2004). An atherogenic blood lipid profile is characterized by increased total

5 cholesterol $\left(\mathrm{T}_{\mathrm{C}}\right)$, low-density lipoprotein cholesterol (LDL-C), and triglycerides (TG) together

6 with reduced high density lipoprotein cholesterol (HDL-c) (Grundy et al. 2005). Diets high in

7 saturated fatty acids (SFA) could promote an atherogenic blood lipid profile, even when total

8 caloric intake is not increased (i.e., eucaloric high-SFA diets). For instance it has been recently

9 reported that the substitution of dietary unsaturated for saturated fatty acids results in marked

10 increases in $\mathrm{T}_{\mathrm{C}}$ and LDL-c after 3 months of intervention (Vessby et al. 2001, Jebb et al. 2010).

11 Even after just 5 weeks of a high saturated fatty acids diet (HSFAD), LDL-c increases have

12 been reported (Allman-Farinelli et al. 2005). While the metabolic effects of sustained

13 increases in total fat and dietary SFA intake are well known, scarce information is available

14 about the effect of short-term increments in SFA intake. This is of potential importance as, for

15 example, a short-term increase in dietary fat intake is common during weekends and holidays

16 (Haines et al. 2003). If a short-term diet is able to deteriorate the blood lipid profile and

17 counter-measures are not established, it is possible that one or repeated bouts of short-term

18 high saturated diet could provoke sustained metabolic disturbances on blood lipids increasing

19 the risk for cardiometabolic diseases development. Additionally, post-prandial lipemia and

20 insulinemia are higher after a high saturated fat meal (Lopez et al.), and post-prandial lipid

21 excursions are linked with cardiovascular disease pathogenesis (i.e., foam cells generation,

22 thrombophylia, endothelial disfunction and oxidative stress; (Ceriello 2000)). To our

23 knowledge, the blood lipid response to a short-term increase in dietary SFA (e.g. two weeks)

24 has not been reported in the literature. 
An increased flux of blood lipids is associated with the development of insulin

2 resistance (Taskinen 2003) in a cause-effect fashion since acute elevations in plasma fatty acids

3 concentrations by intralipid infusion causes increases in insulin resistance (Schenk and

4 Horowitz 2007). Not only the amount but also the saturation of circulating fatty acids may be

5 related to insulin resistance. In fact, in diabetes type 2 patients, 6-week of HSFAD worsens

6 their insulin resistance (Christiansen et al. 1997). However, in non-diabetic but overweight

7 subjects the effects of dietary SFA on insulin sensitivity are not that clear. Some authors have

8 reported decreased insulin sensitivity associated with increases in dietary SFA intake (Vessby

9 et al. 2001), while others did not find differences when monounsaturated fatty acids (MUFA)

10 and polyunsaturated fatty acids (PUFA) are substituted by SFA (Jebb et al. 2010,

11 Haghighatdoost et al. 2012). To our knowledge, it is unclear if a short-term HSFAD would

12 increase insulin resistance in overweight people that habitually consume a low SFA diet (i.e.,

13 Mediterranean population). We think that this question is especially relevant in overweight

14 individuals on account of their recognized increased risk for the development of obesity,

15 dyslipidemia and related cardiometabolic diseases.

16 Exercise training can reduce $\mathrm{TG}, \mathrm{T}_{\mathrm{C}}$, and $\mathrm{LDL}-\mathrm{c}$, and increase HDL-c particularly when

17 caloric expenditure is at least $1200 \mathrm{kcal} \cdot \mathrm{week}^{-1}$ (Durstine et al. 2001). Regular exercise

18 improves the blood lipid profile and enhances insulin sensitivity in previously sedentary adults,

19 even when fat intake is not reduced (Weintraub et al. 1989, Duncan et al. 2003). On the other

20 hand, in overweight people with an atherogenic blood lipid profile, 4 months of supervised

21 aerobic exercise training, enhanced insulin sensitivity (Yoshida et al. 2010) in presence of body

22 weight loss. Improvements in insulin sensitivity have been described after short-term exercise

23 training (seven exercise sessions) in healthy middle-aged men (Tanner et al. 2002). Metabolic

24 short-term training benefits may be even more relevant in people with increased risk factors 
1 (i.e., overweight), and more so when exercise is performed while individuals are consuming a 2 HSFAD.

3 Exercise training in overweight individuals derives not only metabolic but also

4 cardiovascular health benefits (Stensvold et al. 2010). Twelve weeks of aerobic interval

5 training enhances peripheral endothelial function, increases $\mathrm{V} \mathrm{O}_{2 \text { peak }}$ and reduces systolic blood

6 pressure in individuals with abdominal obesity and metabolic syndrome (Stensvold et al.

7 2010). Moreover, 12 weeks of endurance exercise training increased HDL-c and decreased

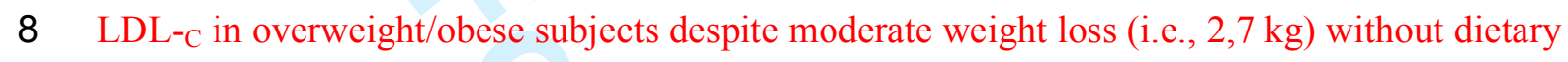

9 intervention (Greene et al. 2012). To our knowledge, there is no information about the

10 cardiovascular adaptations of a short-term exercise training program performed concurrently to

11 a HSFAD. We hypothesized that hyperlipidemia and reduced insulin sensitivity occurred even

12 if the increase in dietary SFA lasted only 2 weeks. We also hypothesized that exercise

13 counteracted the negative metabolic and cardiovascular consequences of a high-SFA diet. 


\section{METHODS}

2 Participants. Fourteen young (24.8 \pm 1.8 years old), overweight (BMI of $27.5 \pm 0.6$

$3 \mathrm{~kg} \cdot \mathrm{m}^{-2}$ ), physically inactive (less than $120 \mathrm{~min}$ per week of moderate/vigorous self-reported

4 physical activity) volunteers were recruited from the University's student and workers

5 population. Participant's basal anthropometric and cardiovascular parameters are presented in

6 Table 1. Women (two in each experimental group) were regularly menstruating and not using

7 oral contraceptives. All subjects were weight stable for the 6 months previous to participation.

8 The study was approved by the local Hospital's Ethics Committee and was conformed to the

9 latest revision of the Declaration of Helsinki.

10 Preliminary testing. All volunteers underwent medical screening, oral glucose

11 tolerance test (OGTT) and a complete blood lipid profile analysis. Medical screening excluded

12 smokers and individuals with heart, metabolic (i.e., diabetes and hyperlipemia), intestinal and

13 pulmonary diseases or those taking medications known to affect the outcome variables. A

14 week before participation in the study subjects underwent a cycling graded exercise stress-test

15 (increasing $25 \mathrm{~W} \cdot \mathrm{min}^{-1}$ until volitional fatigue) with ECG and indirect calorimetry monitoring

16 (Quark B ${ }^{2}$ plus Quark T12, 12-lead telemetry ECG, Cosmed, Italy). Results of this evaluation

17 are depicted in the PRE columns in Table 1.

18 Design. Participants were randomly assigned to a diet alone (D group) or a diet plus

19 exercise training group (D+E group). During 14-days all subjects received a diet that increased

20 their SFA intake while maintaining their habitual total fat and daily calorie intake (Table 2).

21 All ingested fat was individualized and provided to the subjects by the research team. In

22 addition, the seven participants of the $\mathrm{D}+\mathrm{E}$ group received the same diet but underwent 11

23 sessions of aerobic exercise concurrent to the diet. Before and $48 \mathrm{~h}$ after the last training

24 session (D+E group) metabolic and cardiovascular responses were evaluated (Figure 1).

25 Before and after treatments the tests took place after an overnight fast $(>8 \mathrm{~h})$ that followed a 
1 standardized low fat dinner composed of pasta and bread with tomato sauce $(617 \mathrm{kcal} ; 18 \%$

$2 \mathrm{kcal}$ from fat, $69 \% \mathrm{kcal}$ from $\mathrm{CHO}$ and $13 \% \mathrm{kcal}$ from protein).

3 Diet. During the week prior to the start of the study (Pre-week, Figure 1) participants

4 weighted (Delicia, Tefal, France) and recorded all foodstuff and beverages ingested and daily

5 recorded their nude body weight (WildCat; Mettler-Toledo, USA) right after awakening and

6 voiding. Computerized dietary analysis of their records (CESNID, Barcelona, Spain) allowed

7 calculation of daily caloric intake, dietary fat content and composition (i.e., mono-unsaturated;

8 MUFA, polyunsaturated; PUFA, and saturated fatty acids; SFA). During the 14 day

9 intervention, subjects were requested to refrain from all dietary fat sources while were provided

10 by the research team with SFA in the form of whole fat dairy products (i.e., milk, manchego

11 cheese, butter, cream and cheesecake ice-cream). Only the source of fat was substituted and

12 thus calories and total fat intake were maintained (Table 2) with some fluctuation in the D+E

13 group due to the extra food provided after exercise to maintain the energy balance. The snack

14 was composed of an $8 \%$ carbohydrates drink (provided during exercise) and a turkey breast

15 sandwich plus bread with quince jelly, provided right after exercise (i.e., $554 \pm 42 \mathrm{kcal}$ ).

16 Participants were instructed to maintain their habitual ingestion of fruits, vegetables, cereals,

17 bread, pasta and legumes (cooked with the provided butter). During the 14 days of

18 intervention, subjects weighted and recorded the food consumed outside the dependencies of

19 the lab. Diet logs were evaluated daily to check and adjust adherence to the diet intervention.

20 Exercise training. Subjects in the D+E group underwent 11 exercise sessions during

21 55-min on a cycle-ergometer (Ergoline 200, Cosmed, Italy). Exercise started with a 5-min of

$2250 \mathrm{~W}$ warm-up for women and $100 \mathrm{~W}$ for men. After the warm-up, it followed a workload that

23 elicited the $65 \%$ of their individual $\mathrm{V} \mathrm{O}_{2 \text { peak }}$ during 5-min. This absolute workload was

24 replicated during 5-min after the warm-up during the ten remaining exercise sessions with the

25 purpose of evaluating training adaptations on heart rate, gross efficiency, blood lactate and 
1 total fat oxidation rates for a given absolute workload. These $10 \mathrm{~min}$ of exercise were followed

2 by $40-\mathrm{min}$ of exercise at $65 \%$ of their individual $\mathrm{V} \mathrm{O}_{\text {2peak }}$. As training adaptations developed,

3 the workload during those 40 min was progressively increased to maintain target heart rate

4 (Lucia et al. 2000). Sessions concluded with a 5-min cool-down at the same workload of

5 warm-up. Thus, participants cycled for $55 \mathrm{~min}$ at an average intensity of $60 \%$ their

$6 \quad \mathrm{~V} \mathrm{O}_{\text {2peak }}$ when warm-up and cool-down cycling were included.

7 Body composition. Weight and height were measured using a calibrated scale and

8 stadiometer (Seca, Vogel \& Halke, Germany) and BMI was calculated. Percent body fat was

9 estimated by measuring 7 sites skinfold thickness (Holtain Tanner/Whitehouse Skinfold

10 Caliper, Crymich, UK). All measurements were performed by the same technician and percent

11 body fat calculated using gender specific formulae (Jackson and Pollock 1978, Jackson et al.

12 1980).

13 Metabolic measurements. After an overnight fast and at least 48 -h after refraining

14 from exercise, participants lay on a stretcher for 15 minutes in a thermoneutral $\left(21-24^{\circ} \mathrm{C}\right)$,

15 dimly lit quiet room. Resting metabolic rate (RMR) was determined by indirect calorimetry

16 (Quark B ${ }^{2}$, Cosmed, Italy) during 15 minutes after steady-state readings were obtained.

17 Following the RMR measurements, an intravenous catheter (BD Insyte, Becton-Dickinson,

18 Spain) was inserted in an antecubital vein. Five $\mathrm{mL}$ of blood were extracted and the catheter

19 was frequently flushed with $0.9 \%$ saline solution, (Salina Fisiológica, Grifols, Spain) to ensure

20 patency. Five minutes after blood extraction, an oral glucose tolerance test (OGTT) was

21 started with the ingestion of $75 \mathrm{~g}$ of glucose 1-hydrate (Guinama, Spain) diluted into $250 \mathrm{~mL}$

22 of water as proposed by Matsuda and Defronzo (Matsuda and DeFronzo 1999). After 15, 30,

$2345,60,90$ and 120-min of ingesting the glucose load, $5 \mathrm{~mL}$ blood samples were obtained.

24 Samples were mixed in tubes with 3K-EDTA (Vacuette, Greiner Bio-one, Spain) and

25 centrifuged at $4000 \mathrm{rpm}$ during $10 \mathrm{~min}$ at $4^{\circ} \mathrm{C}$ to obtain plasma. Glucose and lactate were 
1 measured immediately with an automated analyzer (EML-105, Radiometer, Denmark) while

2 the remaining of the plasma was stored at $-80^{\circ} \mathrm{C}$ for further analysis. Insulin concentration was

3 analyzed using human insulin ELISA immunoassay technique (96T, Cusabio Biotech Co.,

4 USA). Insulin sensitivity was estimated using the fasting glucose and insulin concentration

5 calculating the HOMA-IR index (Matthews et al. 1985, Haffner et al. 1996) and using the

6 OGTT data, Matsuda insulin sensitivity index was calculated (Matsuda and DeFronzo 1999).

7 Plasma TG, $\mathrm{T}_{\mathrm{C}}$, and $\mathrm{HDL}_{-\mathrm{C}}$ were analyzed using enzymatic assays and a multichannel

8 spectrometer plate reader (Versamax, Molecular Devices, USA). Specifically, TG was

9 analyzed using a glycerol phosphate oxidase reaction (BioSystems, Spain), $\mathrm{T}_{\mathrm{C}}$ using a

10 cholesterol oxidase reaction (BioSystems, Spain) and HDL-c, using an Mg-cholesterol oxidase

11 reaction (BioSystems, Spain). LDL-c was calculated as proposed by Friedewald (Friedewald

12 et al. 1972). Free fatty acids composition was measured using gas chromatography-mass

13 spectrometry (GC/MS; Agilent 5973 Networks, Mass Selective Detector; Agilent

14 Technologies, USA) after calibration with standards of known concentrations (i.e., WAKO

15 Chemicals, Germany). During exercise, substrate utilization and energy expenditure were

16 calculated from indirect calorimetry (Quark $\mathrm{B}^{2}$, Cosmed, Italy). $\mathrm{V} \mathrm{O}_{2}$ and $\mathrm{V} \mathrm{CO}_{2}$ were

17 measured between 3-5 min and 35-40 min during the first, sixth and eleventh exercise session.

18 Fat oxidation rates were calculated using the equation proposed by Frayn (Frayn 1983).

19 Cardio-respiratory measurements. Resting heart rate (HR) and blood pressure were

20 measured just after the RMR assessment. HR was measured using a heart rate monitor (Polar

21 S810i, Finland). Blood pressure was measured in triplicate using an automated blood pressure

22 monitor (Tango Medical Instrument Inc., USA). The day when habitual diet recording started

23 and the day following the end of the experimental interventions (i.e., 48-h after the last exercise

24 bout in D+E group) participants underwent the post OGTT. Then subjects had breakfast and

25 rested for 2-h prior to the post $\mathrm{VO}_{2 \text { peak }}$ assessment on the same cycle-ergometer. After a 
1 standardized 10-min warm-up, the initial power output was set ( $75 \mathrm{~W}$ in men, $50 \mathrm{~W}$ in women)

2 and increased thereafter (i.e., $25 \mathrm{~W} \cdot \mathrm{min}^{-1}$ ) until volitional fatigue or when pedaling cadence

3 dropped repeatedly below $60 \mathrm{rpm}$. Oxygen uptake (i.e., $\mathrm{VO}_{2}$ ) was measured using an

4 automated breath-by-breath indirect calorimetry system (Quark B ${ }^{2}$, Cosmed, Italy) and data

5 was averaged every $15 \mathrm{sec}$. The $\mathrm{V} \mathrm{O}_{2 \text { peak }}$ was defined as the highest $\mathrm{VO}_{2}$ value reached.

6 Statistics. Shapiro-Wilk test was used to assess normal distribution of data. Since the

7 main variable under examination (blood lipid profile) did not show a normal distribution and

8 the sample size was limited, non-parametric statistics were chosen for the analysis (i.e., PRE

9 vs. POST intervention for the $\mathrm{D}$ and $\mathrm{D}+\mathrm{E}$ groups). Wilcoxon test was performed to analyze

10 dependent samples and Mann-Whitney $U$ for independent samples. The level of significance

11 was set at $P<0.05$. Results were reported as means \pm SEM. All the tests were performed with

12 SPSS software version 18.

13 


\section{RESULTS}

2 Body composition. There were no differences between groups in body weight, BMI,

3 and percent body fat before the interventions. BMI, body weight and percent body fat were not

4 different between the beginning and the end of the interventions in any of the groups (Table 1).

Diet manipulation. SFA ingestion increased by approximately $65 \%$ in both groups,

6 and the percent of daily energy intake from SFA in the diet increased $(12.4 \pm 2.7 \%$ to $20.2 \pm$

$7 \quad 4.8 \% ; P<0.001$, Table 2$)$ while percent MUFA $(13.0 \pm 3.8 \%$ to $10.5 \pm 2.2 \% ; P=0.001)$ and

8 PUFA $(7.0 \pm 1.5 \%$ to $2.7 \pm 0.4 \% P<0.001)$ were reduced. In the $\mathrm{D}+\mathrm{E}$ group, energy intake

9 increased (Table 2) as a result of the supplemented food provided to compensate for the energy

10 expenditure during the exercise sessions. The increased energy intake in D+E group was

11 associated with an increased intake of macronutrients, but only fat intake reach a significant

12 difference $(\mathrm{P}=0.028)$. In the $\mathrm{D}$ group, calorie intake decreased $5 \%(\mathrm{NS} ; P=0.093)$, fat intake

13 remained at pre-intervention levels, and as a consequence, relative fat intake increased by $6 \%$

$14 \quad(P=0.047$, Table 2$)$.

15 Exercise training adaptations. The metabolic and cardiovascular adaptations to

16 eleven sessions of exercise are depicted in Table 3. $\mathrm{V} \mathrm{O}_{2 \text { peak }}$ increased in the $\mathrm{D}+\mathrm{E}$ group by 18

$17 \pm 5 \%(P=0.020)$ while it remained unchanged in the D group (Table 1). Average energy

18 expenditure during exercise was $554 \pm 42 \mathrm{kcal}$ and $3048 \pm 208 \mathrm{kcal}$ per week. The work rate

19 needed to elicit the target HR increased $17 \%(P=0.017$; Table 3$)$. As a consequence the

20 energy cost of each exercise session increased across time $(527 \pm 39$ to $580 \pm 41 \mathrm{kcal}$;

$21 \mathrm{P}=0.012$ ). At a given absolute intensity (i.e., $124 \pm 9 \mathrm{~W}$ ), HR and blood lactate were markedly

22 reduced (10 beat $\cdot \min ^{-1}$ and $1.6 \mathrm{mmol} \cdot \mathrm{L}^{-1} ; P=0.019$ and $P=0.022$, respectively; Table 3)

23 while exercise fat oxidation increased 14 fold $(P=0.034$; Table 3$)$ after eleven days of exercise

24 training. Finally, the HR after five minutes of cool-down was significantly lower after training

$25(P<0.001$; Table 3). 
Metabolic measurements. RMR was not different between groups before the

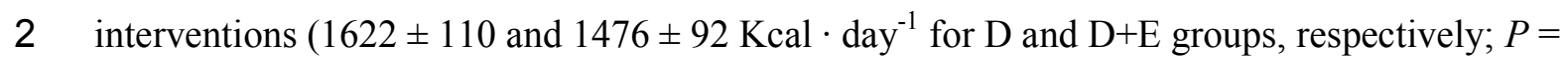

$30.194)$ and did not change after the interventions in any of the two group $(1676 \pm 128 \mathrm{Kcal}$.

4 day $^{-1}, P=0.999$ and $1548 \pm 132 \mathrm{Kcal} \cdot \mathrm{day}^{-1}, P=0.515$ for D and D+E group, respectively).

5 The high SFA diet was associated with a significant increase in $\mathrm{T}_{\mathrm{C}}$ and LDL-c in the $\mathrm{D}$ group

$6 \quad\left(147 \pm 8\right.$ to $161 \pm 9 \mathrm{mg} \cdot \mathrm{dL}^{-1}, P=0.018$ and $71 \pm 10$ to $82 \pm 10 \mathrm{mg} \cdot \mathrm{dL}^{-1}, P=0.034$,

7 respectively; Figure 2), which was prevented in the D + E group $(153 \pm 20$ to $157 \pm 24, P$

$8=0.735$, and $71 \pm 21$ to $70 \pm 25 \mathrm{mg} \cdot \mathrm{dL}^{-1} ; P=0.866$, respectively; Figure 2 ). Plasma

9 concentration of HDL-c, TG and FFA remained unchanged in both groups (Table 4). Before

10 the interventions subjects display similar plasma distribution of FFA $(38.8 \pm 1.1 \%$ of SFA;

$1147.9 \pm 1.3 \%$ MUFA and $13.3 \pm 1.1 \%$ PUFA) which remained unchanged after the intervention

12 in both groups. Of note plasma SFA increased in both groups from $38.8 \pm 1.1 \%$ to $40.3 \pm 1.4$

$13 \%$ without reaching significance $(P=0.253)$.

14 Fasting glucose and insulin did not change as a result of the intervention in any group

15 (Table 4). Therefore, HOMA-IR remained unchanged in the D group and decrease by $24 \%$ in

16 D+E group (i.e., improvement in insulin sensitivity) without reaching significance $(P=0.945$

17 and $P=0.119$, respectively). The insulin sensitivity index calculated from the 120 min OGTT

18 (Matsuda index), remained unchanged in both groups (Table 4). Between groups estimated

19 insulin sensitivity was not different at any time.

20 Cardio-respiratory measurements. In D+E group, there was a significant reduction

21 in resting systolic blood pressure (i.e., $6 \pm 2 \mathrm{mmHg} ; P=0.029$ ) and resting HR (i.e., $9 \pm 3$ beats

$22 \cdot \min ^{-1} ; P=0.027$; Table 1$)$. Conversely, in the $\mathrm{D}$ group there was not a significant change in

23 resting systolic blood pressure or resting HR (Table 1). 


\section{DISCUSSION}

2 During 14 days and under our direct supervision 14 overweight subjects increased by

$365 \%$ their dietary SFA while reducing PUFA and MUFA intake with the aim to maintain total

4 fat intake. As planned, this short-term eucaloric diet did not affect body weight or percent

5 body fat. However, the subjects that received the diet alone (i.e., D group) increased their

6 blood $\mathrm{T}_{\mathrm{C}}$ and LDL-C by 9 and $16 \%$ respectively, (Figure $2 ; P<0.05$ ). This increase was not

7 induced by the last meal ingested (standardized low-fat dinner provided the day before pre and

8 post-intervention testing) but likely to the 14 days exposure to the SFA diet. The most of

9 calories expended during exercise ( $\mathrm{D}+\mathrm{E}$ group) were replaced to avoid the confounding effects

10 of a negative caloric balance. In addition, testing took place $48 \mathrm{~h}$ after the last exercise session

11 (D+E group) with the aim to test the chronic not the acute effects of exercise. On note, short

12 term endurance training (i.e., 11 sessions of 55 min on cycle ergometer at $60 \% \mathrm{~V} \mathrm{O}_{2 \text { peak }}$ )

13 concurrent to a HSFAD prevented the increases in blood cholesterol, while increasing $\mathrm{V} \mathrm{O}_{\text {2peak }}$

14 (i.e., 18\%), fat oxidation and reducing resting systolic blood pressure (i.e., 5\%). Thus, our data

15 suggest that the atherogenic blood lipid profile induced by a short-term high saturated fat diet

16 can be prevented by concurrent aerobic exercise training while improving cardio-respiratory

17 fitness.

18 We are not the first to show increased $T_{C}$ and LDL-C in association with partial

19 substitution of dietary unsaturated by SFA in overweight people (Vessby et al. 2001, Jebb et al.

20 2010). With subjects similarly overweighed (i.e., BMI $\sim 27 \mathrm{~kg} \cdot \mathrm{m}^{-2}$ ) and with a similar dietary

21 intervention (i.e., increases in SFA from 14 to 18\% vs. 12 to 20\% EI presently) Vessby and co-

22 workers reported less increase in blood cholesterol (i.e., $2 \%$ and $4 \%$ for $\mathrm{T}_{\mathrm{C}}$ and LDL-C for

23 Vessby vs. 9\% and 16\% increases, presently). Of note, our subjects had lower pre-intervention

$24 \mathrm{~T}_{\mathrm{C}}\left(150 \mathrm{mg} \cdot \mathrm{dL}^{-1}\right.$ vs. $210 \mathrm{mg} \cdot \mathrm{dL}^{-1}$ in Vessby's data). Thus, it seems that the plasma

25 hyperlipemic response to increased dietary SFA could be also determined by the initial plasma 
1 lipid concentration. In any extent, Vessby’s subjects underwent a 3 month experimental diet,

2 while our intervention lasted merely 2 weeks. To our knowledge, we are the first to show that

3 a two week dietary substitution of unsaturated by SFA, without increasing the absolute amount

4 of fat in diet, could raise blood cholesterol in normolipemic and healthy overweight

5 individuals. We believe that this is relevant since short-term increases in dietary SFA are

6 common during weekends and holidays (e.g., Easter, Christmas, summer breaks) and without a

7 specific intervention (i.e., diet, exercise, medication) the increases in $\mathrm{T}_{\mathrm{C}}$ and $\mathrm{LDL}-\mathrm{C}$ could

8 reach pathological levels (i.e., hyperlipidemia). Additionally, a high saturated fatty acids meal

9 not only results in post-prandial lipemia but also in events linked with cardiovascular disease

10 pathogenesis (i.e., oxidative stress, chylomicron remnants uptake by macrophages, LDL

11 oxidation, and thrombosis activation (Ceriello 2000)).

12 Post-intervention testing was performed 24 hours after the end of the dietary

13 intervention and 48 hours after the last bout of exercise on the D+E group. The $48 \mathrm{~h}$ period was

14 chosen to avoid the confounding effects of the last bout of exercise on blood lipids (i.e., TG

15 decrease and HDL-c increase (Kantor et al. 1984, Grandjean et al. 2000, Crouse et al. 1997)).

16 Crouse et al., (Crouse et al. 1997) reported reductions in LDL-C right after training, while no

17 differences could be observed when comparing before and 48 hours after an exercise session.

18 Similar results were reported by Ferguson et al., (Ferguson et al. 1998) using trained men.

19 They did not observe differences in $\mathrm{T}_{\mathrm{C}}$ and LDL-C between before exercise and 48 hours after

20 exercise of different duration (i.e., 60, 81, 94 and $111 \mathrm{~min}$ of running at $70 \% \mathrm{VO}_{2 \text { peak }}$.). Based

21 on these reports we thought that blood lipid concentrations $48 \mathrm{~h}$ after the last exercise bout

22 would be more likely related to the two weeks of training than to the acute effect of the last

23 exercise session. However, a possible influence of the acute exercise effects on blood lipids

24 cannot be ruled out after $48 \mathrm{~h}$ as it has been recently shown by others (Grandjean et al. 2000,

25 Crouse et al. 1995, Greene et al. 2012). 
Vessby et al., showed that 3 months of increased dietary SFA not only affected blood

2 lipids but also reduced insulin sensitivity in comparison to a group ingesting MUFA when fat

3 intake was above $37 \%$ of daily energy intake. However, in a subsequent study with a higher

4 pool of subjects and a similar intervention, Jebb et al. (Jebb et al. 2010) could not demonstrate

5 an effect of dietary SFA on insulin sensitivity in accordance with a recent report in overweight

6 women (Haghighatdoost et al. 2012). Thus, the effects of increased dietary SFA on insulin

7 sensitivity are not well defined. Our subjects' fat intake was below $37 \%$ of daily energy intake

8 and in accordance to Jebb's data, our indexes that estimate insulin sensitivity remained

9 unchanged in both groups. Noteworthy, our short-term dietary intervention did not raise the

10 percent of SFA in plasma. Longer interventions (i.e. 3 months, (Andersson et al. 2002)) have

11 shown to increase the contribution of SFA to the plasma lipid profile. It is possible that an

12 increased presence of SFA in the circulation may be necessary to provoke insulin resistance

13 when total fat intake is not increased like at present.

14 It is somewhat surprising that eleven session of exercise had such a large impact on

15 cardiovascular health indexes $\left(18 \%\right.$ increase in $\left.\mathrm{V} \mathrm{O}_{2 \text { peak }}\right)$ and $6 \mathrm{mmHg}$ reduction in resting

16 systolic blood pressure), on account that two weeks (6 sessions) of spring interval training in

17 sedentary overweight subjects raises $\mathrm{V} \mathrm{O}_{2 \text { peak }} 8.4 \%$ and lowers resting systolic blood pressure

18 by $6 \mathrm{~mm} \mathrm{Hg}$ (Whyte et al.). Habitual physical activity in our subjects was well below the

19 minimal amount to obtain health benefits (i.e., 150 minutes/week) according to the 2008

20 Physical Activity Guidelines for Americans (U.S. Department of Health and Human Services

21 2008). In fact, our subjects started with a poor cardio-respiratory fitness level (i.e., $\mathrm{V} \mathrm{O}_{2 \text { peak }}$

22 below the $25^{\text {th }}$ percentile matched by gender and age group (Balady 2000)) which may have

23 permitted the large gain in $\mathrm{V} \mathrm{O}_{\text {2peak }}$. Due to the high workout frequency (i.e., 5 sessions per

24 week), our D+E subjects expended $3048 \pm 208$ extra kcal per week which rated our program 
1 as "very vigorous" according to the ACSM and AHA guidelines (Haskell et al. 2007). Our

2 participants received a potentially atherogenic diet and thus we thrive to counteract that

3 potential raising exercise frequency higher than what is usually reported in studies (i.e., 5 vs. 2-

43 days a week). It is possible that a lesser volume and density of exercise could elicit the same

5 cardio-respiratory adaptations observed in our participants, but the interaction of baseline

6 fitness status, volume and intensity of exercise on the achievement of cardiometabolic

7 adaptations are beyond the scope of the present research and further research is necessary to

8 determine if more moderate and feasible exercise programs may have similar beneficial effects.

9 Exercise is a cornerstone intervention in the treatment and prevention of

10 cardiometabolic diseases. The benefits of exercise counteracting risk factors as dyslipidemia

11 and insulin resistance in overweight subjects have been evidenced (Stensvold et al. 2010).

12 Nevertheless, most of the exercise related benefits have been associated with energy deficit and

13 body weight loss. With the aim to assess if exercise was able to prevent a blood lipid profile

14 deterioration or insulin resistance in absence of an energy deficit, we supplemented participants

15 in $\mathrm{D}+\mathrm{E}$ group with food to match the energy spent during the exercise sessions. Despite being

16 in energy balance the $\mathrm{D}+\mathrm{E}$ participants did not increase in $\mathrm{T}_{\mathrm{C}}$ and LDL-c and nevertheless

17 improved cardiometabolic fitness (i.e., resting systolic blood pressure, $\mathrm{V} \mathrm{O}_{2 \text { peak }}$ and fat

18 oxidation rate during exercise). However the 11 exercise sessions neither improve blood lipid

19 profile nor insulin sensitivity. It is possible that a negative carbohydrate balance is needed to

20 increase insulin sensitivity when blood lipids remain unchanged as it has been suggested by

21 other researchers (Harrison et al. 2009, Holtz et al. 2008, Newsom et al. 2010).

22 In summary, we presently show in physically inactive overweight adults that two weeks

23 of substitution of dietary unsaturated for saturated fatty acids worsens their blood lipid profile

24 (increase $\mathrm{T}_{\mathrm{C}}$ and $\mathrm{LDL}-\mathrm{C}$ ) without affecting their insulin sensitivity, body weight or body

25 composition. Furthermore, 11 sessions of aerobic exercise concurrent to the HSFAD 
1 prevented the increase in blood cholesterol and improved parameters associated with

2 cardiovascular health $\left(\mathrm{V} \mathrm{O}_{2 \text { peak }}\right.$ and resting systolic blood pressure).

3 


\section{ACKNOWLEDGMENTS}

2 We would like to thank the participants for their compliance to the treatments. The

3 help of Dr. Juan del Coso and Alvaro López is greatly appreciated. All authors read and

4 approved the final manuscript. This work was partially supported by a grant from the Spanish

5 Ministry of Ciencia e Innovacion (DPS2008-06963). 


\section{REFERENCES}

Allman-Farinelli, M.A., Gomes, K., Favaloro, E.J., and Petocz, P. 2005. A diet rich in high-oleicacid sunflower oil favorably alters low-density lipoprotein cholesterol, triglycerides, and factor VII coagulant activity. J Am Diet Assoc. 105(7): 1071-1079.

Andersson, A., Nalsen, C., Tengblad, S., and Vessby, B. 2002. Fatty acid composition of skeletal muscle reflects dietary fat composition in humans. Am J Clin Nutr. 76(6): 1222-1229.

Balady, G., Berra, K., Golding, L., Gordon, N., Mahler, D., Myers, J., Sheldahl, L. 2000. ACSM's Guidelines for Exercise Testing and Prescription. 6th ed. Philadelphia (PA). Lippincott Williams \& Wilkins,

Ceriello, A. 2000. The post-prandial state and cardiovascular disease: relevance to diabetes mellitus. Diabetes Metab Res Rev. 16(2): 125-132.

Crouse, S.F., O'Brien, B.C., Rohack, J.J., Lowe, R.C., Green, J.S., Tolson, H., and Reed, J.L. 1995. Changes in serum lipids and apolipoproteins after exercise in men with high cholesterol: influence of intensity. J Appl Physiol. 79(1): 279-286.

Crouse, S.F., O'Brien, B.C., Grandjean, P.W., Lowe, R.C., Rohack, J.J., and Green, J.S. 1997. Effects of training and a single session of exercise on lipids and apolipoproteins in hypercholesterolemic men. J Appl Physiol. 83(6): 2019-2028.

Christiansen, E., Schnider, S., Palmvig, B., Tauber-Lassen, E., and Pedersen, O. 1997. Intake of a diet high in trans monounsaturated fatty acids or saturated fatty acids. Effects on postprandial insulinemia and glycemia in obese patients with NIDDM. Diabetes Care. 20(5): 881-887.

Duncan, G.E., Perri, M.G., Theriaque, D.W., Hutson, A.D., Eckel, R.H., and Stacpoole, P.W. 2003. Exercise training, without weight loss, increases insulin sensitivity and postheparin plasma lipase activity in previously sedentary adults. Diabetes Care. 26(3): 557-562. 
Durstine, J.L., Grandjean, P.W., Davis, P.G., Ferguson, M.A., Alderson, N.L., and DuBose, K.D. 2001. Blood lipid and lipoprotein adaptations to exercise: a quantitative analysis. Sports Med. 31(15): 1033-1062.

Ferguson, M.A., Alderson, N.L., Trost, S.G., Essig, D.A., Burke, J.R., and Durstine, J.L. 1998. Effects of four different single exercise sessions on lipids, lipoproteins, and lipoprotein lipase. J Appl Physiol. 85(3): 1169-1174.

Frayn, K.N. 1983. Calculation of substrate oxidation rates in vivo from gaseous exchange. J Appl Physiol. 55(2): 628-634.

Friedewald, W.T., Levy, R.I., and Fredrickson, D.S. 1972. Estimation of the concentration of lowdensity lipoprotein cholesterol in plasma, without use of the preparative ultracentrifuge. Clin Chem. 18(6): 499-502.

Grandjean, P.W., Crouse, S.F., and Rohack, J.J. 2000. Influence of cholesterol status on blood lipid and lipoprotein enzyme responses to aerobic exercise. J Appl Physiol. 89(2): 472-480.

Greene, N.P., Martin, S.E., and Crouse, S.F. 2012. Acute Exercise and Training Alter Blood Lipid and Lipoprotein Profiles Differently in Overweight and Obese Men and Women. Obesity (Silver Spring).

Grundy, S.M., Cleeman, J.I., Daniels, S.R., Donato, K.A., Eckel, R.H., Franklin, B.A., Gordon, D.J., Krauss, R.M., Savage, P.J., Smith, S.C., Jr., Spertus, J.A., and Costa, F. 2005. Diagnosis and management of the metabolic syndrome: an American Heart Association/National Heart, Lung, and Blood Institute Scientific Statement. Circulation. 112(17): 2735-2752.

Haffner, S.M., Kennedy, E., Gonzalez, C., Stern, M.P., and Miettinen, H. 1996. A prospective analysis of the HOMA model. The Mexico City Diabetes Study. Diabetes Care. 19(10): 1138-1141.

Haghighatdoost, F., Hosseinzadeh-Attar, M.J., Kabiri, A., Eshraghian, M., and Esmaillzadeh, A. 2012. Effect of substituting saturated with monounsaturated fatty acids on serum visfatin levels and insulin resistance in overweight women: A randomized cross-over clinical trial. Int J Food Sci Nutr. 
Haines, P.S., Hama, M.Y., Guilkey, D.K., and Popkin, B.M. 2003. Weekend eating in the United States is linked with greater energy, fat, and alcohol intake. Obes Res. 11(8): 945-949.

Harrison, M., O'Gorman, D.J., McCaffrey, N., Hamilton, M.T., Zderic, T.W., Carson, B.P., and Moyna, N.M. 2009. Influence of acute exercise with and without carbohydrate replacement on postprandial lipid metabolism. J Appl Physiol. 106(3): 943-949.

Haskell, W.L., Lee, I.M., Pate, R.R., Powell, K.E., Blair, S.N., Franklin, B.A., Macera, C.A., Heath, G.W., Thompson, P.D., and Bauman, A. 2007. Physical activity and public health: updated recommendation for adults from the American College of Sports Medicine and the American Heart Association. Med Sci Sports Exerc. 39(8): 1423-1434.

Holtz, K.A., Stephens, B.R., Sharoff, C.G., Chipkin, S.R., and Braun, B. 2008. The effect of carbohydrate availability following exercise on whole-body insulin action. Appl Physiol Nutr Metab. 33(5): 946-956.

Jackson, A.S., and Pollock, M.L. 1978. Generalized equations for predicting body density of men. Br J Nutr. 40(3): 497-504.

Jackson, A.S., Pollock, M.L., and Ward, A. 1980. Generalized equations for predicting body density of women. Med Sci Sports Exerc. 12(3): 175-181.

Jebb, S.A., Lovegrove, J.A., Griffin, B.A., Frost, G.S., Moore, C.S., Chatfield, M.D., Bluck, L.J., Williams, C.M., and Sanders, T.A. 2010. Effect of changing the amount and type of fat and carbohydrate on insulin sensitivity and cardiovascular risk: the RISCK (Reading, Imperial, Surrey, Cambridge, and Kings) trial. Am J Clin Nutr. 92(4): 748-758.

Kantor, M.A., Cullinane, E.M., Herbert, P.N., and Thompson, P.D. 1984. Acute increase in lipoprotein lipase following prolonged exercise. Metabolism. 33(5): 454-457.

Lopez, S., Bermudez, B., Ortega, A., Varela, L.M., Pacheco, Y.M., Villar, J., Abia, R., and Muriana, F.J. Effects of meals rich in either monounsaturated or saturated fat on lipid concentrations and on insulin secretion and action in subjects with high fasting triglyceride concentrations. Am J Clin Nutr. 93(3): 494-499. 
Lucia, A., Hoyos, J., Perez, M., and Chicharro, J.L. 2000. Heart rate and performance parameters in elite cyclists: a longitudinal study. Med Sci Sports Exerc. 32(10): 1777-1782.

Matsuda, M., and DeFronzo, R.A. 1999. Insulin sensitivity indices obtained from oral glucose tolerance testing: comparison with the euglycemic insulin clamp. Diabetes Care. 22(9): 1462-1470.

Matthews, D.R., Hosker, J.P., Rudenski, A.S., Naylor, B.A., Treacher, D.F., and Turner, R.C. 1985. Homeostasis model assessment: insulin resistance and beta-cell function from fasting plasma glucose and insulin concentrations in man. Diabetologia. 28(7): 412-419.

Newsom, S.A., Schenk, S., Thomas, K.M., Harber, M.P., Knuth, N.D., Goldenberg, N., and Horowitz, J.F. 2010. Energy deficit after exercise augments lipid mobilization but does not contribute to the exercise-induced increase in insulin sensitivity. J Appl Physiol. 108(3): 554-560.

Nishida, C., Uauy, R., Kumanyika, S., and Shetty, P. 2004. The joint WHO/FAO expert consultation on diet, nutrition and the prevention of chronic diseases: process, product and policy implications. Public Health Nutr. 7(1A): 245-250.

Schenk, S., and Horowitz, J.F. 2007. Acute exercise increases triglyceride synthesis in skeletal muscle and prevents fatty acid-induced insulin resistance. J Clin Invest. 117(6): 1690-1698.

Stensvold, D., Tjonna, A.E., Skaug, E.A., Aspenes, S., Stolen, T., Wisloff, U., and Slordahl, S.A. 2010. Strength training versus aerobic interval training to modify risk factors of metabolic syndrome. J Appl Physiol. 108(4): 804-810.

Tanner, C.J., Koves, T.R., Cortright, R.L., Pories, W.J., Kim, Y.B., Kahn, B.B., Dohm, G.L., and Houmard, J.A. 2002. Effect of short-term exercise training on insulin-stimulated PI 3-kinase activity in middle-aged men. Am J Physiol Endocrinol Metab. 282(1): E147-153.

Taskinen, M.R. 2003. Diabetic dyslipidaemia: from basic research to clinical practice. Diabetologia. 46(6): 733-749. 
U.S. Department of Health and Human Services. 2008 Physical Activity Guidelines for Americans [online]. Available from www.health.gov/paguidelines. [accessed 12 June 2012].

Vessby, B., Uusitupa, M., Hermansen, K., Riccardi, G., Rivellese, A.A., Tapsell, L.C., Nalsen, C., Berglund, L., Louheranta, A., Rasmussen, B.M., Calvert, G.D., Maffetone, A., Pedersen, E., Gustafsson, I.B., and Storlien, L.H. 2001. Substituting dietary saturated for monounsaturated fat impairs insulin sensitivity in healthy men and women: The KANWU Study. Diabetologia. 44(3): 312-319.

Weintraub, M.S., Rosen, Y., Otto, R., Eisenberg, S., and Breslow, J.L. 1989. Physical exercise conditioning in the absence of weight loss reduces fasting and postprandial triglyceride-rich lipoprotein levels. Circulation. 79(5): 1007-1014.

Whyte, L.J., Gill, J.M., and Cathcart, A.J. 2010. Effect of 2 weeks of sprint interval training on health-related outcomes in sedentary overweight/obese men. Metabolism. 59(10): 1421-1428.

Yoshida, H., Ishikawa, T., Suto, M., Kurosawa, H., Hirowatari, Y., Ito, K., Yanai, H., Tada, N., and Suzuki, M. 2010. Effects of supervised aerobic exercise training on serum adiponectin and parameters of lipid and glucose metabolism in subjects with moderate dyslipidemia. J Atheroscler Thromb. 17(11): 1160-1166. 
Table 1. Anthropometric and cardiovascular variables before and after the 2 weeks of treatment in the diet and diet plus exercise groups.

\begin{tabular}{|c|c|c|c|c|c|c|}
\hline & \multicolumn{3}{|c|}{ DIET } & \multicolumn{3}{|c|}{ DIET + EXERCISE } \\
\hline & PRE & POST & $P$ & PRE & POST & $P$ \\
\hline Body Weight (kg) & $86 \pm 4.1$ & $85.7 \pm 4.2$ & 0.387 & $77.4 \pm 2.7$ & $77.1 \pm 2.8$ & 0.421 \\
\hline $\mathrm{BMI}\left(\mathrm{kg} \cdot \mathrm{m}^{-2}\right)$ & $28.6 \pm 1.0$ & $28.5 \pm 1.0$ & 0.196 & $26.4 \pm 0.4$ & $26.3 \pm 0.4$ & 0.397 \\
\hline Body fat $(\%)$ & $23.3 \pm 7.5$ & $23 \pm 7.4$ & 0.108 & $22.3 \pm 5.1$ & $21.9 \pm 5.2$ & 0.059 \\
\hline $\mathrm{SBP}(\mathrm{mmHg})$ & $117 \pm 3$ & $119 \pm 3$ & 0.493 & $123 \pm 3$ & $117 \pm 2$ & $0.029 *$ \\
\hline DBP $(\mathrm{mmHg})$ & $68 \pm 2$ & $68 \pm 3$ & 1.000 & $69 \pm 2$ & $66 \pm 3$ & 0.257 \\
\hline Resting HR (beats $\cdot \min ^{-1}$ ) & $62 \pm 6$ & $60 \pm 4$ & 0.573 & $69 \pm 5$ & $60 \pm 4$ & 0.027 * \\
\hline$\dot{\mathrm{VO}}_{2 \text { peak }}\left(\mathrm{ml} \cdot \mathrm{kg}^{1} \cdot \mathrm{min}^{-1}\right)$ & $35.2 \pm 3.3$ & $34 \pm 2.9$ & 0.144 & $36.2 \pm 2.5$ & $42.3 \pm 2.8$ & 0.020 * \\
\hline
\end{tabular}

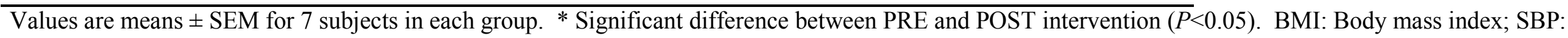

Systolic blood pressure; DBP: Diastolic blood pressure; HR: Heart rate; $\mathrm{V} \mathrm{O}_{2 \text { peak }}$ : Peak oxygen consumption. 
Table 2. Dietary intake before and after the 2 weeks of treatment in the diet and diet plus exercise groups.

\begin{tabular}{|c|c|c|c|c|c|c|}
\hline & \multicolumn{3}{|c|}{ DIET } & \multicolumn{3}{|c|}{ DIET + EXERCISE } \\
\hline & PRE & POST & $P$ & PRE & POST & $P$ \\
\hline $\begin{array}{l}\text { Energy Intake } \\
\left(\mathrm{kcal}^{\prime} \text { day }^{-1}\right)\end{array}$ & $2405 \pm 234$ & $2273 \pm 244$ & 0.093 & $2138 \pm 99$ & $2436 \pm 143$ & $0.027 *$ \\
\hline $\begin{array}{c}\text { Carbohydrates } \\
\left(\mathrm{g} \cdot \text { day }^{-1}\right)\end{array}$ & $247 \pm 25$ & $236 \pm 30$ & 0.310 & $256 \pm 10$ & $307 \pm 24$ & 0.063 \\
\hline $\begin{array}{l}\text { Proteins } \\
\left(\mathrm{g} \cdot \text { day }^{-1}\right)\end{array}$ & $108 \pm 17$ & $107 \pm 12$ & 0.921 & $93 \pm 6$ & $96 \pm 5$ & 0.699 \\
\hline $\begin{array}{l}\text { Fat intake } \\
\left(\mathrm{g} \cdot \text { day }^{-1}\right)\end{array}$ & $90 \pm 9$ & $89 \pm 10$ & 0.738 & $74 \pm 6$ & $83 \pm 7$ & $0.028 *$ \\
\hline $\begin{array}{l}\text { Fat intake } \\
(\% \text { of } E I)\end{array}$ & $34.3 \pm 2.9$ & $36.2 \pm 36.2$ & $0.047 *$ & $31.1 \pm 1.5$ & $31.0 \pm 2$ & 0.690 \\
\hline $\begin{array}{l}\text { SFA intake } \\
\left(\mathrm{g} \cdot \text { day }^{-1}\right)\end{array}$ & $32 \pm 4$ & $53 \pm 6$ & $0.001 *$ & $31 \pm 4$ & $51 \pm 4$ & $<0.001 *$ \\
\hline $\begin{array}{l}\text { SFA intake } \\
(\% \text { of EI) }\end{array}$ & $11.9 \pm 1.1$ & $21.7 \pm 2.1$ & $<0.001 *$ & $12.9 \pm 1.0$ & $18.8 \pm 1.4$ & $0.003 *$ \\
\hline
\end{tabular}

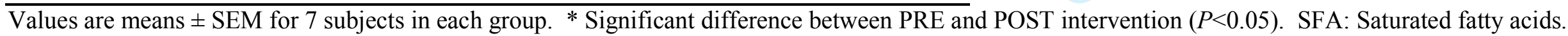


Table 3. Training-related adaptations in the diet plus exercise group.

\begin{tabular}{|c|c|c|c|}
\hline & \multicolumn{3}{|c|}{ DIET + EXERCISE } \\
\hline & $1^{\mathrm{ST}}$ session & $11^{\mathrm{TH}}$ session & $P$ \\
\hline $\begin{array}{c}\text { Heart Rate } \\
\left(\text { beat } \cdot \min ^{-1}\right) \dagger\end{array}$ & $149 \pm 3$ & $139 \pm 4$ & $0.019 *$ \\
\hline $\begin{array}{l}\text { Blood lactate } \\
\left(\mathrm{mmol} \cdot \mathrm{L}^{-1}\right)\end{array}$ & $5.4 \pm 0.5$ & $3.8 \pm 0.3$ & $0.022 *$ \\
\hline $\begin{array}{c}\text { WR at target HR } \\
\text { (Watts) } \dagger\end{array}$ & $124 \pm 9$ & $145 \pm 11$ & 0.017 * \\
\hline $\begin{array}{l}\text { Fat oxidation rates } \\
\qquad\left(\mathrm{g} \cdot \mathrm{min}^{-1}\right)\end{array}$ & $\begin{array}{l}0.01 \pm \\
0.01\end{array}$ & $\begin{array}{l}0.14 \pm \\
0.04\end{array}$ & $0.043 *$ \\
\hline $\begin{array}{l}\text { Recovery HR } \\
\left(\text { beats } \cdot \min ^{-1} \text { ) }\right.\end{array}$ & $142 \pm 3$ & $130 \pm 4$ & $<0.001 *$ \\
\hline
\end{tabular}

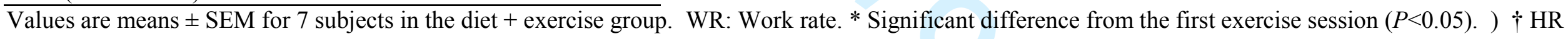
at a fixed work rate $(124 \pm 9 \mathrm{~W}) .+$ Target $\mathrm{HR}$ : $\mathrm{HR}$ at $\left.65 \% \quad \mathrm{~V} \mathrm{O}_{2 \text { peak }}\right)$. 
Table 4. Carbohydrate and fat blood variables prior and after the 2 weeks of treatment in the diet and diet and exercise groups.

\begin{tabular}{|c|c|c|c|c|c|c|}
\hline & \multicolumn{3}{|c|}{ DIET } & \multicolumn{3}{|c|}{ DIET + EXERCISE } \\
\hline & PRE & POST & $P$ & PRE & POST & $P$ \\
\hline $\begin{array}{l}\text { Fasting glucose } \\
\quad\left(\mathrm{mg} \cdot \mathrm{dL}^{-1}\right)\end{array}$ & $92 \pm 2$ & $94 \pm 2$ & 0.299 & $92 \pm 2$ & $91 \pm 2$ & 0.397 \\
\hline $\begin{array}{l}\text { Fasting Insulin } \\
\quad\left(\mu \mathrm{U} \cdot \mathrm{dL}^{-1}\right)\end{array}$ & $23 \pm 7$ & $23 \pm 7$ & 0.959 & $23 \pm 5$ & $19 \pm 4$ & 0.184 \\
\hline HOMA-IR & $5.3 \pm 1.7$ & $5.4 \pm 1.7$ & 0.945 & $5.1 \pm 1.2$ & $3.9 \pm 0.8$ & 0.119 \\
\hline Matsuda Index & $3.0 \pm 0.7$ & $3.2 \pm 0.7$ & 0.673 & $2.7 \pm 0.4$ & $3.0 \pm 0.4$ & 0.111 \\
\hline $\begin{array}{c}\mathrm{HDL}-\mathrm{C} \\
\left(\mathrm{mg} \cdot \mathrm{dL}^{-1}\right)\end{array}$ & $59 \pm 3$ & $61 \pm 3$ & 0.325 & $65 \pm 4$ & $68 \pm 4$ & 0.118 \\
\hline $\begin{array}{l}\text { Triglycerides } \\
\left(\mathrm{mg} \cdot \mathrm{dL}^{-1}\right)\end{array}$ & $85 \pm 6$ & $87 \pm 7$ & 0.907 & $87 \pm 19$ & $96 \pm 16$ & 0.343 \\
\hline $\begin{array}{c}\text { FFA } \\
\left(\mathrm{nmol} \cdot \mathrm{mL}^{-1}\right)\end{array}$ & $455 \pm 46$ & $417 \pm 49$ & 0.866 & $428 \pm 85$ & $422 \pm 52$ & 0.612 \\
\hline
\end{tabular}

HDL-c: High density lipoprotein cholesterol; TG: Triglycerides; FFA: Free fatty acids. 


\section{FIGURES CAPTIONS}

Figure 1. Experimental design. Habitual diet was recorded during the Pre-week. $\square$ Days of experimental diet. $\square$ Supervised cycle-ergometer training. Test Experimental testing

Figure 2. A) Total cholesterol (i.e., $\mathrm{T}_{\mathrm{C}}$ ) and $\mathrm{B}$ ) Low density lipoprotein (i.e., LDL-c) after 14 days of high SFA diet (D) and diet plus concurrent aerobic exercise training (D+E). Data are means \pm SEM for 7 subjects in each group. * Denotes difference between PRE and POST intervention $(P<0.05)$. 


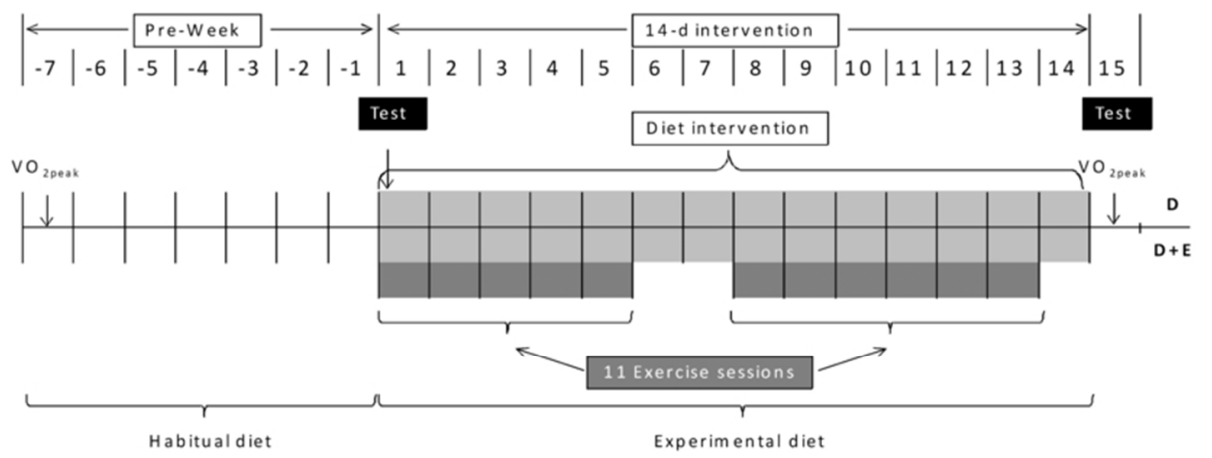

Experimental design. Habitual diet was recorded during the Pre-week. $\square$ Days of experimental diet. $\square($ Gray $)$ Supervised cycle-ergometer training. - Experimental testing $76 \times 29 \mathrm{~mm}(300 \times 300 \mathrm{DPI})$ 

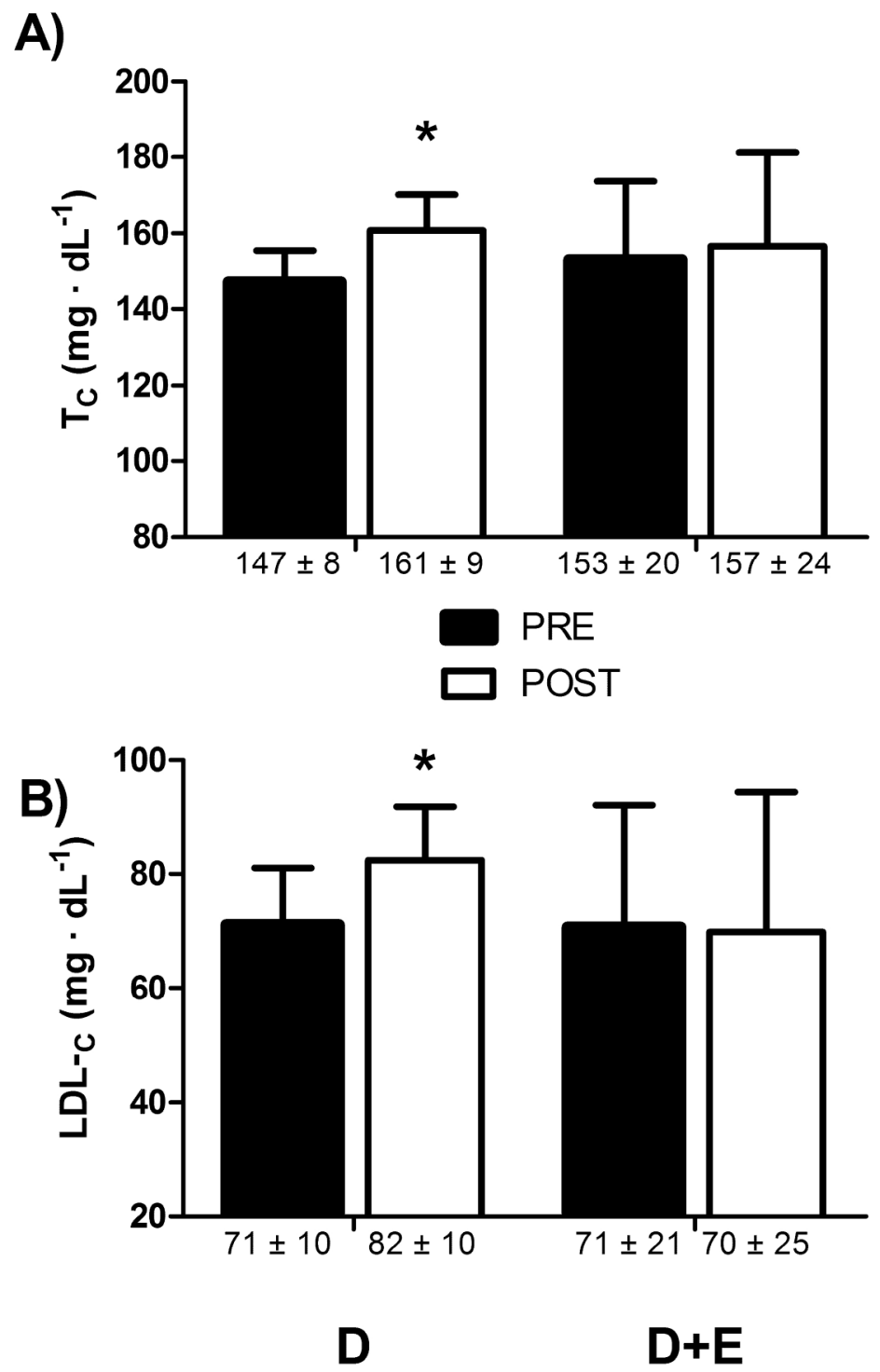

A) Total cholesterol (i.e., TC) and B) Low density lipoprotein (i.e., LDL-C) after 14 days of high SFA diet (D) and diet plus concurrent aerobic exercise training $(D+E)$. Data are means $\pm S E M$ for 7 subjects in each group. * Denotes difference between PRE and POST intervention $(P<0.05)$. $199 \times 275 \mathrm{~mm}(300 \times 300 \mathrm{DPI})$ 